\title{
Water-flow rates and passive diffusion partially explain differential survival of corals during the 1998 bleaching event
}

\author{
T. Nakamura, R. van Woesik*
}

Department of Chemistry, Biology and Marine Science, The University of the Ryukyus, Senbaru 1, Nishihara, Okinawa 903-0213, Japan

\begin{abstract}
In the western Pacific during 1998, coral bleaching, or the paling of corals through loss of pigmentation or loss of symbiotic algae (zooxanthellae), coincided with some of the warmest sea-surface temperatures (SSTs) on record. However, there was considerable spatial variation in coral survivorship; for example, corals of the same species at different locations around the Ryukyu Islands (Japan), within kilometers of each other, showed vastly different responses. Some locations experienced $100 \%$ coral mortality while other locations, nearby, suffered little coral mortality. Here we show experimental evidence for high survivorship of Acropora digitifera coral colonies that were subjected to both high SSTs (ranging from 26.22 to $33.65^{\circ} \mathrm{C}$ ) and high-water flow (50 to $70 \mathrm{~cm} \mathrm{~s}^{-1}$ ), while corals that were subjected to both high SSTs and low-water flow (2 to $3 \mathrm{~cm} \mathrm{~s}^{-1}$ ) showed low survivorship. All experiments were conducted under high irradiance ( $\sim 95 \%$ photosynthetically active radiation). We also empirically show that no coral mortality occurred when SSTs were below $30^{\circ} \mathrm{C}$ (ranging from 26.64 to $29.74^{\circ} \mathrm{C}$ ) under similar flow regimes. The spatial differences in coral mortality during the 1998 bleaching event may have been, in part, a result of differences in water-flow rates that induced differential rates of passive diffusion, which varied among habitats.
\end{abstract}

KEY WORDS: Coral bleaching $\cdot$ Water-flow rates $\cdot$ Passive diffusion

Resale or republication not permitted without written consent of the publisher

The mass transfer of gases and metabolites is necessary for the maintenance, growth and reproduction of all marine organisms (Dennison \& Barnes 1988, Atkinson et al. 1994, Lesser et al. 1994, Thomas \& Atkinson 1997). Water flowing across marine organisms exerts forces on those organisms. Those forces generate a frictional drag (i.e., shear stress) that allows mass transfer across the diffusion-limiting boundary layers which lie between the surrounding (bulk) water and the organism (Patterson \& Sebens 1989). Thick bound-

${ }^{*}$ Corresponding author. E-mail: b984138@sci.u-ryukyu.ac.jp ary layers exist around marine organisms in lowflow environments, while in high-flow environments boundary layers are thin. Therefore, rough morphologies are an advantage in habitats with low-water velocities because rough morphologies increase frictional drag, thereby increasing the mass-transfer potential (Baird \& Atkinson 1997, Bruno \& Edmunds 1998). Thus, forced convection of water across marine organisms enhances shear stress that in turn greatly promotes passive diffusion (i.e., not involving energy) of metabolites or heat across the boundary between the organism and the ambient environment. Zero water flow would suggest diffusion to equilibrium, which would in turn severely restrict metabolic processes and, especially in multi-branched coral colonies, probably lead to death.

The theory. The relationship between shear stress and water velocity can be understood with reference to Newton's law of viscosity:

$$
\tau=\left[\left(\rho U^{2}\right) / 2\right] C_{\mathrm{D}}
$$

where $\tau$ is the shear stress (or force per unit area exerted by the water, $\left.\mathrm{kg} \mathrm{m}^{-2} \mathrm{~s}^{-1}\right), \rho$ is the density of water $\left(998.4 \mathrm{~kg} \mathrm{~m}^{-3}\right), U$ is water velocity $\left(\mathrm{m} \mathrm{s}^{-1}\right)$ and $C_{\mathrm{D}}$ is the drag coefficient of the object or organism. This equation shows that small increases in (water) velocity enhance the shear stress by the square of the velocity. Flux of dissolved gases and metabolites, between an organism and the surrounding water, is also largely dependent on the size and morphology of the organism (Lesser et al. 1994). A dimensionless Sherwood number $\left(\mathrm{Sh}_{0}\right)$, often used in aquatic plant allometry (Niklas 1994), quantifies gas-flux theory as

$$
\mathrm{Sh}_{0}=k_{\mathrm{c}} W / D_{\mathrm{v}}
$$

where $k_{\mathrm{c}}$ is the diffusion rate $\left(\mathrm{m} \mathrm{s}^{-1}\right), W$ is the organism's characteristic dimension $(\mathrm{m})$, and $D_{\mathrm{v}}$ is the diffusivity $\left(\mathrm{m}^{2} \mathrm{~s}^{-1}\right)$, which is equivalent to the mass diffusiv- 
ity/molecular diffusivity; thus the rate of mass transfer is equivalent to $k_{\mathrm{c}}=\mathrm{Sh}_{0} D_{\mathrm{v}} / W$. Another dimensionless number is the Reynolds number, which again relates to the dimensional characteristics of an organism, $W(\mathrm{~m})$, the velocity of the water, $U\left(\mathrm{~m} \mathrm{~s}^{-1}\right)$, the fluid's density, $\rho$ $\left(\mathrm{kg} \mathrm{m}^{-3}\right)$, and the dynamic viscosity of the water, $\mu$ (kg $\mathrm{m}^{-1} \mathrm{~s}^{-1}$ ). The Reynolds number is defined as

$$
\operatorname{Re}=\rho U W / \mu
$$

Patterson (1992) showed that the relationship between $\mathrm{Sh}_{0}$ and $\mathrm{Re}$ follows a power function:

$$
\mathrm{Sh}_{0}=C \operatorname{Re}^{d}
$$

where $C$ is a constant and $d$ is a flow size exponent for mass transfer through a laminar or turbulent boundary layer. Patterson noted how this relation closely followed the plot of body size and metabolic rate, and by solving the 3 equations simultaneously (i.e., Eqs. 2 to 4 ) the rate of diffusion (or mass transfer) can be formally stated as:

$$
k_{\mathrm{c}}=\left(c D_{\mathrm{v}} W^{d-1} \rho^{d} U^{d}\right) / \mu^{d}
$$

Coral bleaching. From extensive field observations around Okinawa (Japan) we noticed a high survival of corals in high water-flow habitats (R.v.W. pers. obs.). Our hypothesis is that the coral colonies growing in high water-flow habitats are more resistant to a combination of high sea-surface temperatures (SSTs) and high irradiance than colonies in low water-flow habitats under the same SSTs and irradiance. Our rationale is as follows. Excessively high irradiance causes a reduction in the photosynthetic activity of plants. This phenomenon, referred to as photo-inhibition, involves the inactivation of the photosynthetic apparatus by the accumulation of harmful superoxides and other oxygen radicals that interfere with photosynthetic processes (Asada 1999). Harmful oxygen radicals also accumulate in endosymbiotic zooxanthellae when the corals are subjected to both high irradiance and high SSTs (Lesser 1997, Jones et al. 1998, Warner et al. 1999). Reducing or removing oxygen radicals, or their more permeable derivatives, may ensure colony survival. High water-flow habitats may induce high-mass transfer of any detrimental photosynthetic byproducts. We test this hypothesis experimentally.

Methods. Modelling: The theoretical relationships among mass transfer, the organism's size and water velocity were derived by solving Eq. (5). Our input parameters were: $C$ (a constant), equal to $2 ; D_{\mathrm{v}}$ (the diffusion coefficient of the dissolved species), which for $\mathrm{O}_{2}$ in water is equal to $2 \times 10^{-9} \mathrm{~m}^{2} \mathrm{~s}^{-1} ; W$ (the organism's characteristic dimension, either length or height above the benthos) was varied from 0.01 to $0.45 \mathrm{~m}$; $d$ (a flow size exponent), equal to 0.5 for mass transfer through a laminar-boundary layer and 0.8 for mass transfer through a turbulent boundary layer (after Patterson 1992); $\rho$ (the fluid's density), equal to $998.4 \mathrm{~kg}$ $\mathrm{m}^{-3} ; U$ (the water velocity), input at $0.2,0.4$ and $0.8 \mathrm{~m}$ $\mathrm{s}^{-1}$; and $\mu$ (the dynamic viscosity of water) $0.001 \mathrm{~kg} \mathrm{~m}^{-1}$ $\mathrm{s}^{-1}$.

Empirical methods: To test the above theory we undertook the following experiments in July-August 2000 at the Tropical Biosphere Research Center, University of the Ryukyus, Sesoko Island, Okinawa, Japan. Three Acropora digitifera colonies were collected from Bise reef (Okinawa). (Bise reef is near Sesoko Island, but has on average higher water-flow rates and most Acropora colonies below $8 \mathrm{~m}$ survived the 1997-98 bleaching event.) Small multi-branched colonies (ranging from 4.7 to $6.8 \mathrm{~cm}$ in height and 2.0 to $3.2 \mathrm{~cm}$ in diameter) were broken off each colony and allowed to heal for 2 wk in an outdoor aquarium maintained under $30 \%$ photosynthetically active radiation (PAR) and $\sim 3 \mathrm{~cm} \mathrm{~s}^{-1}$ water flow.

We then subjected the small branches to different water-flow rates and SST conditions. Water-flow rate treatments were maintained at 50 to $70 \mathrm{~cm} \mathrm{~s}^{-1}$ and at $3 \mathrm{~cm} \mathrm{~s}^{-1}$. One SST treatment ranged from 26.22 to $33.65^{\circ} \mathrm{C}$ and the other, acting as the control, ranged from 26.64 to $29.74^{\circ} \mathrm{C}$. Corals were maintained in Perspex mini-flumes (length $140 \mathrm{~cm}$, width $10 \mathrm{~cm}$, and height $10 \mathrm{~cm}$, while the water was constantly 5 to $6 \mathrm{~cm}$ deep) (adapted from Atkinson \& Bilger 1992). These mini-flumes were supported on concrete blocks within an open aquarium (length $2.5 \mathrm{~m}$, width $1.3 \mathrm{~m}$, and depth $0.4 \mathrm{~m}$ ) that was supplied with running seawater. Five replicates from each colony were placed in each treatment. For stability the replicates were attached to $30 \times 7 \mathrm{~cm}$ acrylic plates using Kneadit Selleys underwater cement. All treatments and controls were subjected to $95 \%$ PAR. The water-flow rates in the mini-flumes were generated and maintained with submersible pumps (REI-SEA, Type RSD-40).

Results and discussion. We solved Eq. (5) for a number of input parameters (Fig. 1). Here, $k_{\mathrm{c}}$ predicts that the mass transfer or rates of diffusion, within a given surface area, to and from small organisms is more rapid than to and from large organisms (Fig. 1). An implicit assumption of this theory is that if the organisms are coral colonies then they have no spatial context; that is, they have no neighbors inducing turbulence, which is not often the case in the field. Therefore in theory, if high-mass transfer is critical in times of stress, for example, when SSTs are high, small colonies are expected to survive in preference to large colonies under similar flow regimes. Indeed, Loya et al. (in press) show that small colonies of Acropora corals survived in preference to large colonies of Acropora in the same habitat, which suggests that the theory and the empirical evidence concur. 


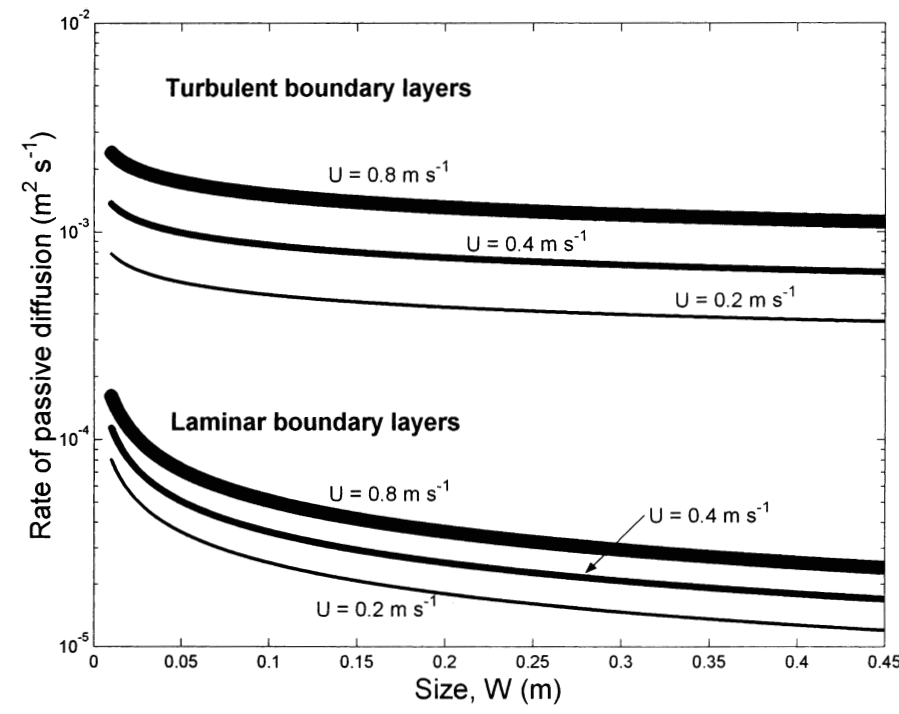

Fig. 1. Theoretical relationships among mass transfer, the organism's size and water velocity, derived by solving Eq. (5) $-k_{\mathrm{C}}=\left(c D_{\mathrm{v}} W^{d-1} \rho^{d} U^{d}\right) / \mu^{d}$ - where $k_{\mathrm{c}}$ is the mass transfer coefficient $\left(\mathrm{m}^{2} \mathrm{~s}^{-1}\right) ; C$ is a constant (here 2$) ; D_{\mathrm{v}}$ is the diffusion coefficient of the dissolved species (here for $\mathrm{O}_{2}$ in water equaling $\left.2 \times 10^{-9} \mathrm{~m}^{2} \mathrm{~s}^{-1}\right) ; W$ is the organism's characteristic dimension (m) (here modeled as 0.01 to 0.45 ); $d$ is a flow-size exponent, here input at 0.5 to 0.8 , to simulate mass transfer through laminar and turbulent boundary layers respectively; $\rho$ is the fluid's density, $998.4 \mathrm{~kg} \mathrm{~m}^{-3}$; $U$ is the water velocity $\left(\mathrm{m} \mathrm{s}^{-1}\right.$ ) (here taken to be $0.8,0.4$ and $0.2 \mathrm{~m} \mathrm{~s}^{-1}$ ); and $\mu$ is the dynamic viscosity of water at $0.001 \mathrm{~kg} \mathrm{~m}^{-1} \mathrm{~s}^{-1}$

Theory also suggests that water velocity is a ratedetermining step in mass transfer (Fig. 1). We solved Eq. (5) for different water velocities. Clearly, mass transfer increases with increasing water flow. Fig. 2 shows high coral survival in high water-flow treatments, even though the corals were subjected to high SSTs (i.e., when SSTs ranged from 26.22 to $33.65^{\circ} \mathrm{C}$ ), while low-water flow treatments, at the same temperatures, induced coral bleaching and mortality within 8 d. At slightly lower SSTs, $<30^{\circ} \mathrm{C}$ (i.e., ranging from 26.64 to $29.74^{\circ} \mathrm{C}$ ), under the same irradiance, there was no coral mortality in either high or low watervelocity treatments. We hypothesized that the coral colonies growing in high water-flow habitats are more resistant to a combination of high SSTs and high irradiance than colonies in low water-flow habitats under the same SSTs and irradiance. The results of the experiments support the hypothesis.

High-water flow may sequester, through diffusion, the build-up of toxins within corals subjected to high SSTs and high irradiance. Jones et al. (1998), and Warner et al. (1999) showed convincing evidence that the onset of coral bleaching, under high SSTs and high (solar) irradiance, begins by the impairment of $\mathrm{CO}_{2}$ fixation under high temperature and high irradiance. Jones et al. (1998) suggested that the toxic oxygen pro-
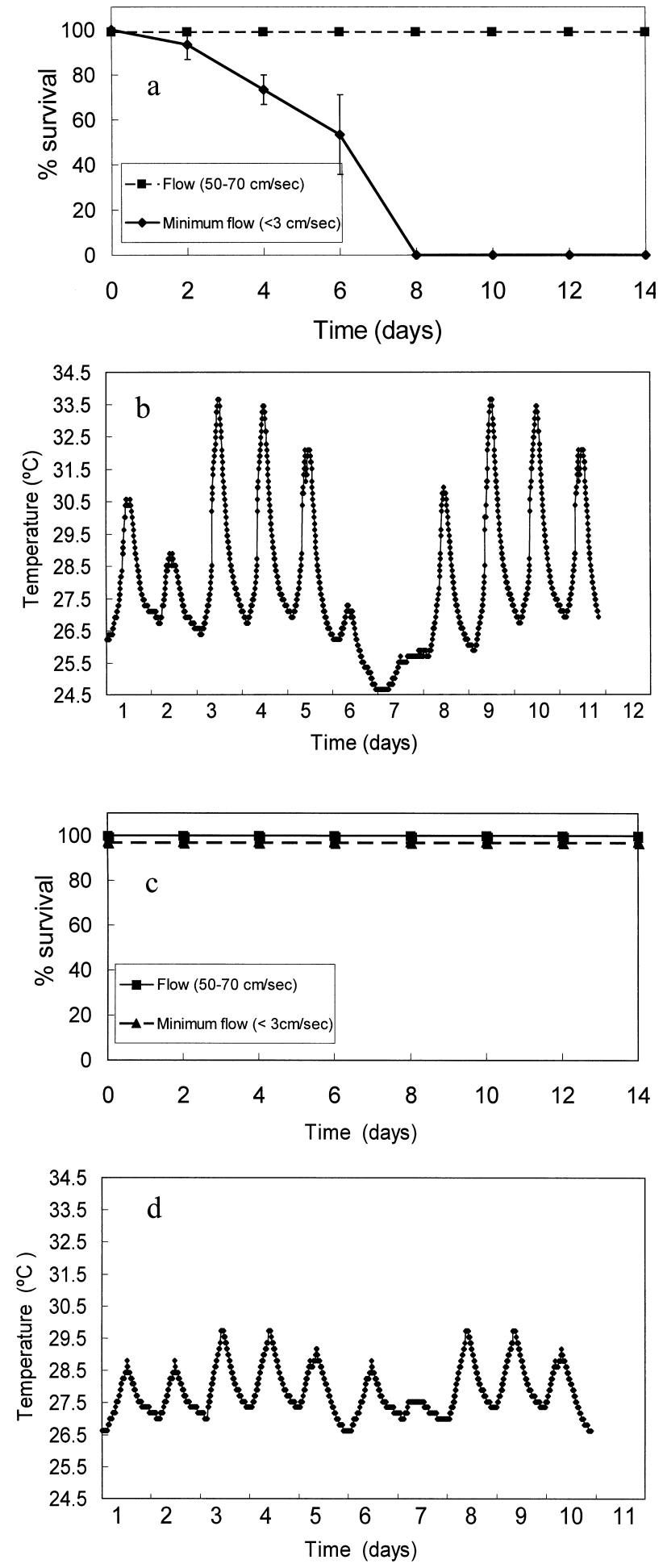

Fig. 2. $(\mathrm{a}, \mathrm{c})$ Survival rates of Acropora digitifera branches $(\mathrm{n}=$ 15) (a) at high sea-surface temperatures (SSTs) and (c) at low SSTs $(\mathrm{n}=11)$. Note that minimal flow survival was $100 \%$ in (c), but was reduced by $2 \%$ for (presentation) clarity. (b,d) Actual water temperatures, presented below the respective survivorship curves. Means and standard errors of survival are shown as points and whiskers respectively 
duced in zooxanthellae at high SSTs coupled with irradiance could damage pigments and proteins that lead to the inactivation of photosynthesis. Although oxygen radicals are not particularly permeable, superoxides are easily converted to more permeable hydroxyl radicals, which can diffuse easily through cells and cell membranes (Yamasaki 2000). Therefore, oxygen radicals and their derivatives, produced by zooxanthellae at high SSTs coupled with high irradiance, could potentially damage pigments and proteins that lead to the inactivation of photosynthesis, and could indeed induce coral bleaching. The removal of these molecules may prevent photosynthetic inactivation and hence prevent coral bleaching. Further experiments are needed that trace the evolution and diffusion rates of toxic molecules, under high SSTs and high irradiance, in corals. In conclusion, these simple physical principles may explain why the 1998 coral bleaching effects in the Ryukyu Islands, Japan, were patchy and why sites with high-flow rates also had high coral survival.

Acknowledgements. We would like to thank the Research Institute of the Subtropics (Okinawa) and Monbusho (Japan), grant number 12480166, for supporting this study.

\section{LITERATURE CITED}

Asada K (1999) The water-water cycle in chloroplasts: scavenging of active oxygens and dissipation of excess photons. Annu Rev Plant Physiol Plant Mol Biol 50:601-639

Atkinson MJ, Bilger RW (1992) Effects of water velocity on phosphate uptake in coral reef-flat communities. Limnol Oceanogr 37:273-279

Atkinson MJ, Kotler E, Newton P (1994) Effects of water velocity on respiration, calcification, and ammonium uptake of a Porites compressa community. Pac Sci 48: 296-303

Editorial responsibility: Charles Birkeland (Contributing Editor), Honolulu, Hawaii, USA
Baird ME, Atkinson MJ (1997) Measurement and prediction of mass transfer to experimental coral reef communities. Limnol Oceanogr 42(8):1685-1693

Bruno JF, Edmunds PJ (1998) Metabolic consequences of phenotypic plasticity in the coral Madracis mirabilis (Duchassaing and Michelotti): the effect of morphology and water flow on aggregate respiration. J Exp Mar Biol Ecol 229:187-195

Dennison WC, Barnes DJ (1988) Effect of water motion on coral photosynthesis and calcification. J Exp Mar Biol Ecol 115:67-77

Jones RJ, Hoegh-Guldberg O, Larkum AWD, Schreiber U (1998) Temperature-induced bleaching of corals begins with impairment of the $\mathrm{CO}_{2}$ fixation mechanism in zooxanthellae. Plant Cell Environ 21:1219-1230

Lesser MP (1997) Oxidative stress causes coral bleaching during exposure to elevated temperatures. Coral Reefs 16: 187-192

Lesser MP, Weis VM, Patterson MR, Jokiel PL (1994) Effects of morphology and water motion on carbon delivery and productivity in the reef coral, Pocillopora damicornis (Linnaeus): diffusion barriers, inorganic carbon limitation, and biochemical plasticity. J Exp Mar Biol Ecol 178:153-179

Loya Y, Sakai K, Yamazato K, Nakano Y, Sambali H, Van Woesik R (in press) Coral bleaching: the winners and the losers. Ecol Lett

Niklas KJ (1994) Plant allometry: the scaling of form and process. University of Chicago Press, Chicago

Patterson MR (1992) A mass-transfer explanation of metabolic scaling relations in some aquatic invertebrates and algae. Science 255:1421-1423

Patterson MR, Sebens KP (1989) Forced convection modulates gas exchange in cnidarians. Proc Natl Acad Sci USA 86: 8833-8836

Thomas FIM, Atkinson ML (1997) Ammonium uptake by coral reefs: effects of water velocity and surface roughness on mass transfer. Limnol Oceanogr 42(1):81-88

Warner ME, Fitt WF, Schmidt GW (1999) Damage to photosymbiotic dinoflagellates: a determinant of coral bleaching. Proc Natl Acad Sci USA 96:8007-8012

Yamasaki H (2000) Nitrite-dependent nitric oxide production pathway: implications for involvement of active nitrogen species in photoinhibition in vivo. Phil Trans R Soc Lond B Biol Sci 355:1477-1488

Submitted: September 17, 2000; Accepted: December 15, 2000 Proofs received from author(s): February 12, 2001 